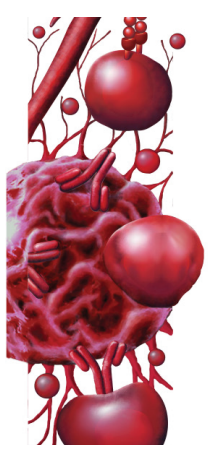

\title{
Vaccination in patients with primary immune deficiency, secondary immune deficiency and autoimmunity with immune regulatory abnormalities
}

\begin{abstract}
Vaccination has been an important healthcare measure in preventing infectious diseases. The response to vaccination is reduced in immunocompromised patients, primary immune deficiency (PID) and secondary immune deficiency (SID), but vaccination studies still demonstrated a protective effect resulting in reducing complications, hospitalization, treatment costs and even mortality. The primary physician and the specialist directing patient care are responsible for vaccination. Live vaccines are contraindicated in patients with severe immune impairment, killed vaccines are highly recommended in PID and SID. Criteria have been defined to distinguish high- or low-level immune impairment in the different disease entities among PID and SID patients. For patients who do not respond to diagnostic vaccination as characterized by antibody failure immunoglobulin replacement is the mainstay of therapy.
\end{abstract}

Keywords: immunodeficiency $\bullet$ immunization $\bullet$ primary $\bullet$ secondary $\bullet$ timing $\bullet$ vaccination

Infectious complications are a major cause of morbidity and mortality in patients with primary immunodeficiency, secondary immunodeficiency and patients with immune modulatory abnormalities leading to auto-immune disease often treated with immune-suppressive and/or immune-modulatory drugs and biologicals [1-5]. Prevention of infectious diseases by available vaccines is among the most effective and most important healthcare measures. Vaccines, for example, against polio, measles, mumps, rubella, whooping cough, hepatitis $A$ and $B$, infection with Haemophilus influenzae b, pneumococci, meningococci or papilloma virus, protect against debilitating and severe diseases with potentially deadly complications, especially in the immunocompromised [6-15]. Vaccination against these diseases had a major impact on morbidity and mortality, especially in, but not limited to, the pediatric population.

Vaccination of the great majority of the susceptible healthy population will not only prevent disease in the vaccinated but will also lead to herd immunity. Herd immunity would help to protect the weakest segment of the population which is especially susceptible to infection and too young or immune-compromised to be successfully vaccinated $[16,17]$. Guidelines recommend vaccination as part of medical care especially for immunocompromised patients, for example, for patients with primary immune deficiency (PID) disorders and for subgroups of patients with secondary immune deficiency (SID) also including patients with autoimmune diseases, in other words, with immune-regulatory abnormalities (IRA) [18-21]. The Infectious Diseases Society of America (the IDSA) recommends that the primary care clinician and respective specialist following the patient are responsible for assuring vaccination of immunocompromised patients [22]. It is often emphasized that adults in general and especially immunocompromised individuals are highly undervaccinated [23-26].

The scope of this review is to raise awareness of the importance of vaccination to physicians who are taking care of immunocompromised patients and to the specialists
Martha M Eib|*,1 \& Hermann $M$ Wolf ${ }^{1}$

${ }^{1}$ Immunology Outpatient Clinic, Schwarzspanierstrasse 15,1090 Vienna, Austria

*Author for correspondence: martha.eibl@meduniwien.ac.at 
following or giving advice for treatment of patients with PID, SID and/or IRA. Even though there are extensive yearly updated recommendations for vaccination also for patient populations who are considered to be at great risk for infectious disease, for example, diabetes, this group is still considered to be highly undervaccinated by disease-specific expert committees [27-30]. This short review presents some of the special requirements needed to be considered for patients with impairment of immune function with respect to contraindications, timing and dosing of vaccination as compared with the recommendations of vaccination effective for the general population.

\section{Definition \& diagnosis of PID}

PID disorders are a heterogeneous group of diseases caused by more than 200 known single gene mutations that lead to impairment of innate or adaptive immunity [31,32]. A single site mutation may cause alterations in the number of immune cell subsets or in the expression of immune receptors or their ligands and/or in the expression of differentiation markers. Impairment of function in well-defined cell activation pathways occurs as a consequence. Typically patients with PID present with increased susceptibility to infections. In addition, it became more and more clear through studies published in recent years that the spectrum of clinical manifestations in PID often includes autoimmune and systemic inflammatory diseases, as the only clinical symptoms or as primary clinical manifestations before the susceptibility to infections develops [33-35].

PID diagnosis requires a careful evaluation of various arms of immunity depending on the clinical presentation of the patient. These include white blood cell counts and differential assessment of lymphocyte subsets including $\mathrm{T}$ - and $\mathrm{B}$-cell numbers and $\mathrm{T}$ - and $\mathrm{B}$-cell subsets, as well as the examination of serum immunoglobulin levels, IgG subclasses, antibody responses following exposure to infection or vaccination, the study of T-cell activation, cytokine release, proliferation and effector functions (e.g., cell-mediated cytotoxicity). Furthermore, components of the innate immune 1 system to be investigated include assessment of the complement system (activation via the classical, lectin and alternative pathway, and quantification of the individual complement components), examination of NK-cell-mediated cytotoxicity, assessment of phagocyte numbers and functions, for example, generation of reactive oxygen radicals [31]. According to the cell types/function involved, the following forms of PID disorders have been categorized: combined immunodeficiency, combined immunodeficiencies with associated or syndromic features, predominantly antibody deficiencies, diseases of immune dysregulation, congenital defects of phagocyte number, function or both, defects in innate immunity, autoinflammatory disorders, complement deficiencies [31]. Hematopoietic stem cell transplantation (HSCT) is a curative treatment for severe combined T- and B-cell defects. Other, less severe $\mathrm{T}$ and $\mathrm{B}$ cell defects (combined immunodeficiency) will have to be treated according to the prevailing immunological phenotype of the individual patient. These patients might require HSCT if the T cell defect is prominent and/or vaccination/immunoglobulin treatment if the antibody deficiency prevails. Predominantly antibody deficiencies represent at least $50 \%$ of all clinically symptomatic PIDs and thus need special consideration with respect to vaccination. Antibody production can be measured by testing antibody responses following infection or natural exposure. In addition, antibodies against vaccination antigens can be examined in patients with a positive vaccination history [29]. Diagnostic vaccination with killed vaccines is considered to be safe and important, as it aims to directly recognize impairment of antibody production which might be helpful to make treatment decisions earlier than by applying surrogate markers such as hypogammaglobulinemia and/or B-cell differentiation markers and recurrent infections [36,37]. On the other hand, assessment of binding antibodies also means using surrogate markers for antibody deficiency, because these assays do not directly measure functional, for example, neutralizing, opsonizing and/or bactericidal antibodies [38]. However, there is a certain degree of correlation as, for example, both binding and neutralizing antibodies increase upon vaccination [39-42]. This allows for the setting of threshold values corresponding to $95 \%$ seroconversion of neutralizing/bactericidal titers. A more detailed discussion regarding antibody quality is beyond the scope of this article [43-46]. Results of diagnostic vaccination could facilitate diagnosis of antibody deficiency syndromes and facilitate the decision for early treatment with immunoglobulins [37]. Increased susceptibility to infections has to be identified on an individual basis, and determining the response to vaccination against diseases that contribute to morbidity and mortality in these populations is clinically useful for risk assessment $[47,48]$.

Assessment of the severity of impaired antibody formation after diagnostic vaccination with killed/ inactivated vaccines identifies a group of patients with highest risk for infection. PID patients with a severe impairment in antibody production, either because of an intrinsic B-cell defect or due to a combined immunodeficiency affecting both $\mathrm{T}$ - and B-cell immunity are also those with a higher risk to develop severe, potentially lethal adverse reactions after vaccination with 
Table 1. Usage of vaccines in patients with primary immune deficiency.

$\begin{array}{ll}\text { Underlying } & \text { Vaccines recommended for the general } \\ \text { immunological defect } & \text { population } \\ \text { in PID } & \end{array}$

in PID

Severe combined immune-deficiency, e.g., XL-SCID Severe antibody deficiency, e.g., XLA, CVID

Less severe impairment of antibody production, e.g., IgG-SD, SPAD

Less severe impairment

immunity, e.g., partial

T-cell deficiency such as

DiGeorge syndrome,

Complement deficiency
Usage of generally recommended vaccines is also recommended for patients with severe defects in adaptive immunity. Primary immunization should follow the same rules. More frequent booster immunizations might be required depending on the assessment of antibody and cellular vaccination responses. Patients with SCID require stem cell transplantation and should be vaccinated after immunological reconstitution. Partial/incomplete immune protection has to be expected after vaccination with inactivated vaccines in patients with severe antibody deficiency
Generally recommended vaccines that are contraindicated in PID

All live vaccines. It is notable that immunoglobulin replacement therapy induces passive immune protection against several infections that could otherwise be prevented by live vaccines, e.g., measles, mumps, rubella, VZV; in addition, antibodies contained in immunoglobulin preparations interfere with the development of active immunity after vaccination, e.g., MMR
Vaccines especially recommended for use in PID patients ${ }^{\dagger}$

Inactivated Influenza PCV and/or PPSV23

(PCV > PPSV23)

conjugated Hib
None due to the immunodeficiency
Inactivated Influenza PCV and/or PPSV23

(PCV > PPSV23)

conjugated Hib

All live vaccines; consider MMR and VZV vaccine in less severe immune deficiency PCV and/or PPSV23

(PCV > PPSV23) of cell-mediated

Inactivated influenza

conjugated Hib

PCV and/or PPSV23

(PCV > PPSV23)

conjugated Hib, tetravalent conjugated (ACW135Y) and meningococcal $B$ vaccine

Phagocyte defects

MSMD

Autoinflammatory

disorders

Functional or anatomical

asplenia
Live bacterial vaccines are contraindicated

Live bacterial vaccines are contraindicated

None due to the

immunodeficiency; in case of immunosuppressive treatment see autoimmune diseases

None due to the immunodeficiency
None due to the immunodeficiency

None due to the immunodeficiency

PCV and/or PPSV23

(PCV > PPSV23) conjugated $\mathrm{Hib}$, tetravalent conjugated (ACW135Y) and meningococcal $B$ vaccine 
live vaccines [49]. In patients with severe antibody deficiency, intravenously or subcutaneously administered immunoglobulin replacement therapy remains the mainstay of treatment [50-52]. Diagnostic vaccination with inactivated vaccines can and should be administered as part of assessment of the immune response before the decision regarding initiation of immunoglobulin treatment is made [53]. There are no general safety concerns regarding killed vaccines in PID, SID and IRA [49]. Discussion whether vaccination might induce neurological conditions such as encephalopathy or autism, and autoimmune disease such as diabetes, are always brought up by anti-vaccination activists and have been analyzed with great scrutiny. According to recent reports there is no indication of vaccination causing these conditions [54-56].

As killed vaccines are considered to be safe, diagnostic vaccination - booster immunization with pneumococcal conjugate vaccine (PCV) and, in patients $>2$ years, with 23-valent unconjugated pneumococcal polysaccharide vaccine (PPSV23), a polysaccharide vaccine or primary vaccination, for example, with tickborne enzephalitis virus vaccine (TBEV) or inactivated influenza vaccine is strongly recommended in patients with suspected PID [37]. Evaluating antibody response to a primary antigen may provide information regarding a patient's ability to mount an antibody response against a novel infectious agent. It is of note that for diagnostic purposes vaccination with live vaccines is contraindicated [49].

\section{Vaccination in PID}

It is well established that patients with different forms of PID have an increased susceptibility to infections. Infections may be lethal in early childhood, especially in patients with severe combined immune-deficiency and certain forms of other combined immune deficiency syndromes or in patients with severe phagocyte defects, for example, chronic granulomatosis disease (CGD). Recurrent bacterial infections such as pneumococcal, Haemophilus influenzae type b (Hib) and staphylococcal infections were often lethal in the second decade of life, before immunoglobulin treatment was established, and are still a significant cause of chronic lung disease in patients with variable forms of predominantly antibody syndromes such as common variable immunodeficiency (CVID). Categorization of a patient's immunodeficiency is helpful in the assessment of the risk-benefit ratio for vaccination [49]. Detailed recommendations including the degree/ disease-special immune impairment differentiates, for example, primary complement deficiencies, phagocyte defects, innate immune defects, minor antibody deficiencies, major antibody deficiencies, combined immu- nodeficiencies and severe combined immunodeficiency (SCID) [22].

While vaccination with live vaccines, such as rotavirus vaccine, varicella zoster virus (VZV) and measles mumps rubella (MMR) vaccine or bacillus CalmetteGuérin (BCG), is principally contraindicated in patients with severe impairment of immunological function, this is not the case in populations with no or minimal impairment of adaptive immunity or in patients with defects in innate immunity. Inactivated vaccines recommended for the general population are principally also indicated in patients with PID (Table 1). Primary immunization should follow the same rules as used in the general population. Safety data for individual vaccines have been evaluated by several studies, thus giving a basis for the recommendations. Although it is likely that incomplete protection is induced through vaccination with killed/inactivated vaccines if an impairment in specific immunity is present, in most cases even a partial protective effect clearly outweighs the minimal or nearly nonexistent risk associated with the use of an inactivated, toxoid or recombinant vaccine [57-64]. In a controlled randomized trial of 9-valent pneumococcal conjugated vaccine (PCV9) in children with and without HIV infection, 19,922 children received PCV9 and 19,914 received placebo. Among noninfected recipients the protection of invasive pneumococcal disease among controls was $83 \%$ and in HIV-infected children 65\%. [57]. For this reason, all killed/inactivated vaccines used in the general population have been recommended in immunocompromised patients as well [22].

Live vaccines will multiply in the host and interact with host cells in this process. These vaccines are attenuated and might cause symptoms similar to the infection by the disease-causing agent, but the degree is mild or minimal in immunocompetent individuals. These vaccines, however, may be lethal and cause severe/disseminated disease in patients with immunosuppression [49]. For this reason, oral polio vaccine (OPV) and BCG vaccination are contraindicated in all immunocompromised populations as OPV might revert to wild type virus years after infection $[22,65]$. A few countries in the world, including the USA, switched to inactivated polio vaccine (IPV); the rest of the world including 19 member states of the European Union, most of Africa, the Middle East and Asia are still using OPV, and at present OPV is, on its own or with IPV, the only vaccine in the polio eradication program by the WHO. Other live vaccines recommended for the healthy population, for example, MMR, varicella zoster, rotavirus vaccine, live attenuated influenza vaccine are contraindicated in all PID and SID patients with severe impairment of immune function/high-grade 
immunosuppression [49,66,67]. In patients with lowlevel immune suppression the respective recommendations have to be adhered to and/or risk/benefit has to be assessed on an individual basis by an experienced clinician [49,67], for example, in patients with DiGeorge syndrome and mild-to-moderate immune deficiency where live vaccines might be well tolerated [68]. Special attention has been paid to immunization with varicella zoster vaccine in immunocompromised individuals, as the infection with this attenuated vaccine strain can be devastating in the immunocompromised population [49]. Varicella (VAR), a live vaccine, should not be administered to patients with PID and SID severely affecting T-cell-mediated immunity [22].

OPV and BCG are contraindicated in all PID patients $[22,65]$. All live vaccines are contraindicated in patients with severe immunodeficiency disorders and in patients with immunodeficiency disorders with $<500 \mathrm{CD} 4$ cells $/ \mathrm{mm}^{3}$ (adults), $<1000 \mathrm{CD} 4$ cells $/ \mathrm{mm}^{3}$ (1-6 years of age) or $<1500 \mathrm{CD}^{+}$cells $/ \mathrm{mm}^{3}(<1$ year of age), respectively, as has been recommended for PID patients [49].

In patients with 'leaky' forms of (S)CID who have more CD4 cells, or in patients with suspected combined immunodeficiency, individual assessment of risk and benefit of the use of live vaccine such as MMR and VZV by experienced clinicians may take other decisions into consideration [49]. In patients with major antibody deficiencies who are on immunoglobulin treatment, live vaccines are contraindicated and inactivated vaccines are recommended as in the healthy population $[22,28,29]$. Some patients have antibody failure against bacterial polysaccharide antigens but are able to respond to immunization with protein antigens. Vaccination with protein antigens might be advantageous, even though they are receiving immunoglobulin treatment. Although they will likely fail to induce complete immunoprotection, it cannot be excluded that a partial immune response induced by vaccination contributes to the protective effect provided by the antibodies delivered through the immunoglobulin replacement therapy. For example, a T-cell response has been shown in X-linked agammaglobulinemia (XLA) [58-62,69]. Furthermore, vaccination-induced immunoglobulin $\mathrm{M}(\mathrm{IgM})$ antibodies might reduce infectious episodes in patients with impaired immunoglobulin $\mathrm{G}$ antibody production receiving IgG replacement therapy, as has been shown in common variable immunodeficiency patients [59].

As outlined before, diagnostic application of inactivated vaccines is part of the immune response assessment to decide on initiation of immunoglobulin treatment in patients with suspected major antibody deficiency $[37,70]$. In other forms of predominantly antibody deficiency, for example, immunoglobulin A (IgA) deficiency or selective polysaccharide antibody deficiency, provided that other (cellular and humoral) immune system components are normal, routine vaccination based on the Centers for Diseases Control and Prevention (CDC) annual recommendation should be adhered to, certain inactivated vaccines are especially recommended and usage of other licensed inactivated vaccines that are not particularly recommended should be considered [28,29].

Disease-specific recommendations for inactivated vaccines and contraindications for live vaccines exist for patients with innate immune defects, for example, use of live bacterial vaccines is contraindicated in patients with defects in the IFN- $\gamma /$ IL-12 pathway, and live viral vaccines are contraindicated in patients with defective IFN- $\alpha$ function $[22,49]$. There are no general contraindications regarding the use of live vaccines in patients with phagocyte defects except for certain live attenuated bacterial vaccines mainly used in travelers, for example, live typhoid vaccine. Special age/cell type/mechanism/disease-specific recommendations are given for primary complement deficiencies and primary phagocyte deficiency such as CGD, leucocyte adhesion deficiency etc. These groups should receive all routinely recommended vaccines based on the annual schedule for vaccination. Patients with complement deficiencies may receive live vaccines based on the immunological assessment of the individual patient showing intact adaptive immunity $[21,49]$.

\section{Definition \& diagnosis of secondary immune deficiencies}

Patients with SIDs are a continuously increasing heterogenous group [71]. Patients with SIDs have an increased risk for infectious disease $[20,27,72]$. Vaccinepreventable infectious diseases lead to increased morbidity and mortality in this population. In addition to a severe course, the infectious disease can also have deleterious effects on the underlying disease, for example, progression of malignancies, rejection of transplants and major difficulties in the treatment of certain autoimmune diseases [73-75]. In SID populations, long-and short-term prophylaxis of infections mainly relies on vaccination and antimicrobial chemoprophylaxis [25,76]. Numerous small and medium-sized studies, as well as meta analysis taking into account results of several different studies clearly show that vaccination with influenza, Hib and hepatitis vaccines, as well as meningococcal conjugate vaccine (MCV), PCV, PPSV can save lives and/or reduce hospitalization, intensive care treatment and treatment costs in this group of patients [64,77-81]. However, randomized controlled studies of large populations are not 
available in most instances. In this situation, recommendations are given by experts taking into account that class I evidence is not available. As results of new studies are evaluated, yearly recommendations are adapted accordingly. This might also be the reason for discrepant views in individual publications.

Populations at high risk for infections include segments of the general population, for example, the elderly, pregnant women, premature infants and young children, as well as patients with SID and patients with autoimmune diseases $[14,16,17,82,83]$. Secondary immunodeficiencies develop in the course of the underlying heterogenous diseases or in consequence of immune-suppressive treatment. The impairment in immune defense may be at various levels and involves multiple mechanisms contrary to the monogenic pathogenesis seen in PID. Individual patients with SID can be affected by immunodeficiency to a different extent at different stages during the course of the underlying disease. This is likely the reason that even fairly large studies in a single disease entity irrespective of the immune impairment of individual patients are inconclusive [84]. Secondary immune deficiencies are less well-defined than PIDs, but their clinical relevance is increasingly recognized [20]. Comparable to PID, patients with SIDs may be susceptible to different types of pathogens depending on the underlying immune defect, for example, viral and/or opportunistic infections in diseases with nonfunctional or absent $\mathrm{T}$ cells and mainly bacterial infections in antibody failure syndromes $[2,70,75]$. Respiratory or GI tract infections may occur more frequently, be life threatening and also occur with generally less pathogenic or difficult to treat organisms in patients with SID [33,85].

\section{Vaccination in SID}

Vaccination is strongly recommended in these populations to reduce morbidity and mortality, complications leading to hospitalization and increase in healthcarerelated costs [28,29,86]. Most vaccines recommended for the healthy population including children and adults are also recommended for the group with impaired immunity. However, indications and contraindications have to be analyzed taking into consideration the degree of impairment in immune function. High-level immune suppression may be transient after stabilization of the disease and will be followed by treatment with low-grade immune suppression [81]. This has been taken into consideration in recommendations for vaccination for individual disease entities [87]. The definition of high-level and low-grade immunosuppression in immunocompromised adults by the Advisory Committee on Immunization Practices (ACIP) or IDSA may serve as a guideline for evaluating the extent of immunodeficiency in SID (Table 2). Immune-suppressive treatment may be followed by high- and/or lowlevel impairment of immune function, depending on the time and the extent of therapy, the drugs used and/ or whether biologicals are applied. For example, highlevel immunosuppression occurs in patients receiving cancer chemotherapy, within 2 months after solid organ transplantation, in patients with HIV-infection and with a CD4 T-lymphocyte count $<200$ cells $/ \mathrm{mm}^{3}$ for adults and adolescents and percentage $<15 \%$ for infants and children below the age of 6 years, in patients receiving daily corticosteroid therapy with a dose $\geq$ than $20 \mathrm{mg}$ (or $>2 \mathrm{mg} / \mathrm{kg} /$ day for patients who weigh $<10 \mathrm{~kg}$ ) of prednisone or equivalent for $\geq 14$ days, and, receiving certain biologic immune modulators such as a TNF- $\alpha$ blocker or an anti-CD20 monoclonal antibody. There are special recommendations after HSCT and for patients on low-level immune suppression, as well as disease-specific recommendations taking into consideration the patients' age, the type of hematological malignancy or solid tumor and the drugs or biologics used [22].

The experienced clinician will recommend vaccination on an individual basis, after evaluating risk/benefit based on the results of assessment of the patient's immunocompetence, taking into consideration clinical history and laboratory tests. The following immunological laboratory tests will aid in this decision: blood count with differential, lymphocyte subsets, complement hemolytic activity, determination of individual complement components, serum immunoglobulin concentrations and IgG subclasses, antibody titers after natural exposure to infection or previous vaccination, response to primary and booster immunization with a polysaccharide antigen and a protein antigen. Additional functional studies on a cellular level may be required. For patients under severe immune suppression who cannot mount an adequate immune response to vaccination, as demonstrated by diagnostic vaccination or examination of antibody titers following infection or previous vaccination, antibody replacement by the intravenous or subcutaneous route (short- or longterm) is feasible and recommended [88]. Most present recommendations for Ig replacement in SID include patients with hypgogammaglobunemia and/or proven antibody deficiency and recurrent infections. The aim of treatment is to prevent severe, potentially lethal infection (acute mortality), to prevent infection leading to chronic organ damage, to slow down the course of disease in patients in whom organ damage has already occurred (chronic lung disease, chronic liver disease etc.) and to prevent complications leading to a more severe course of the disease. 
Vaccination in immunodeficient populations Review

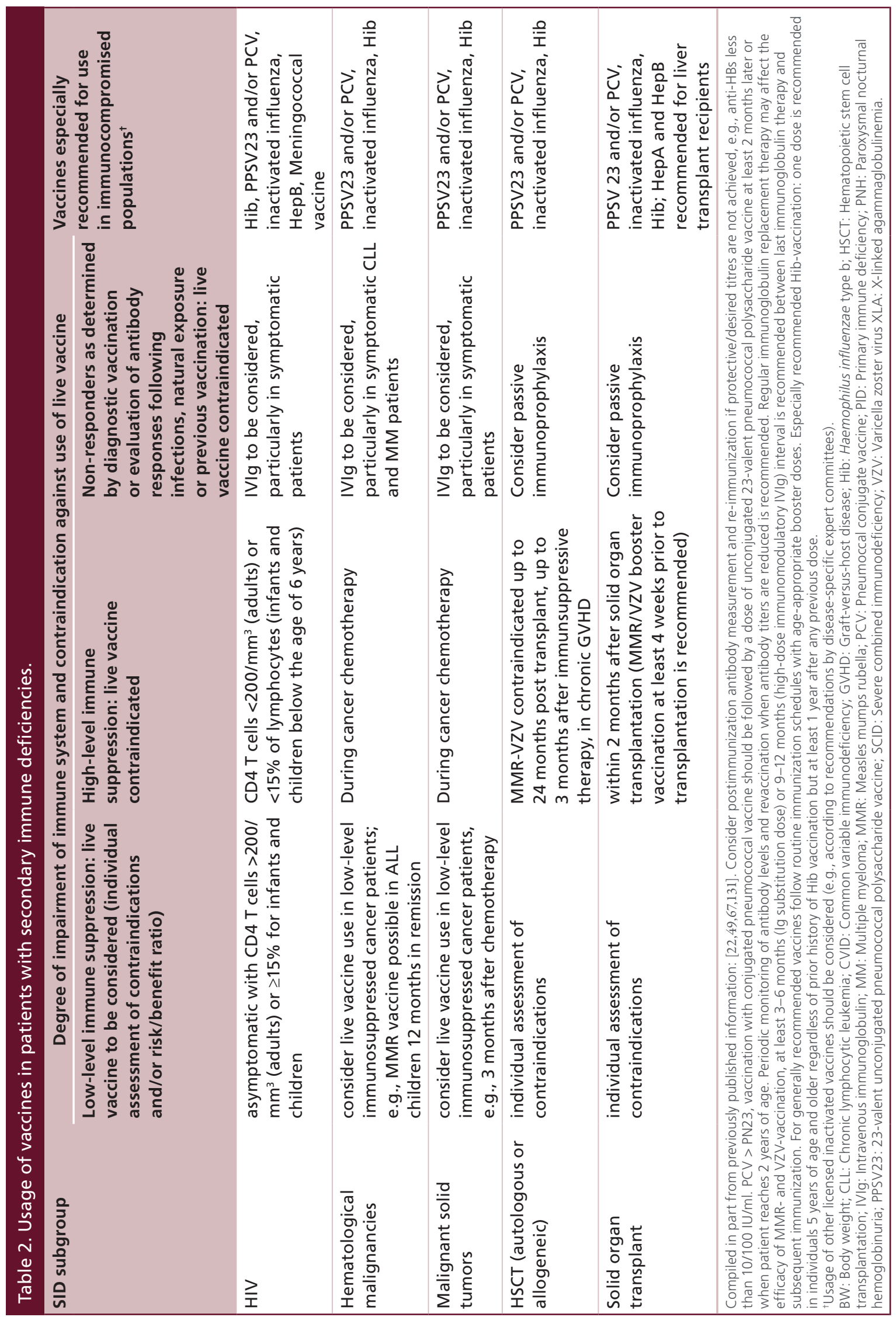




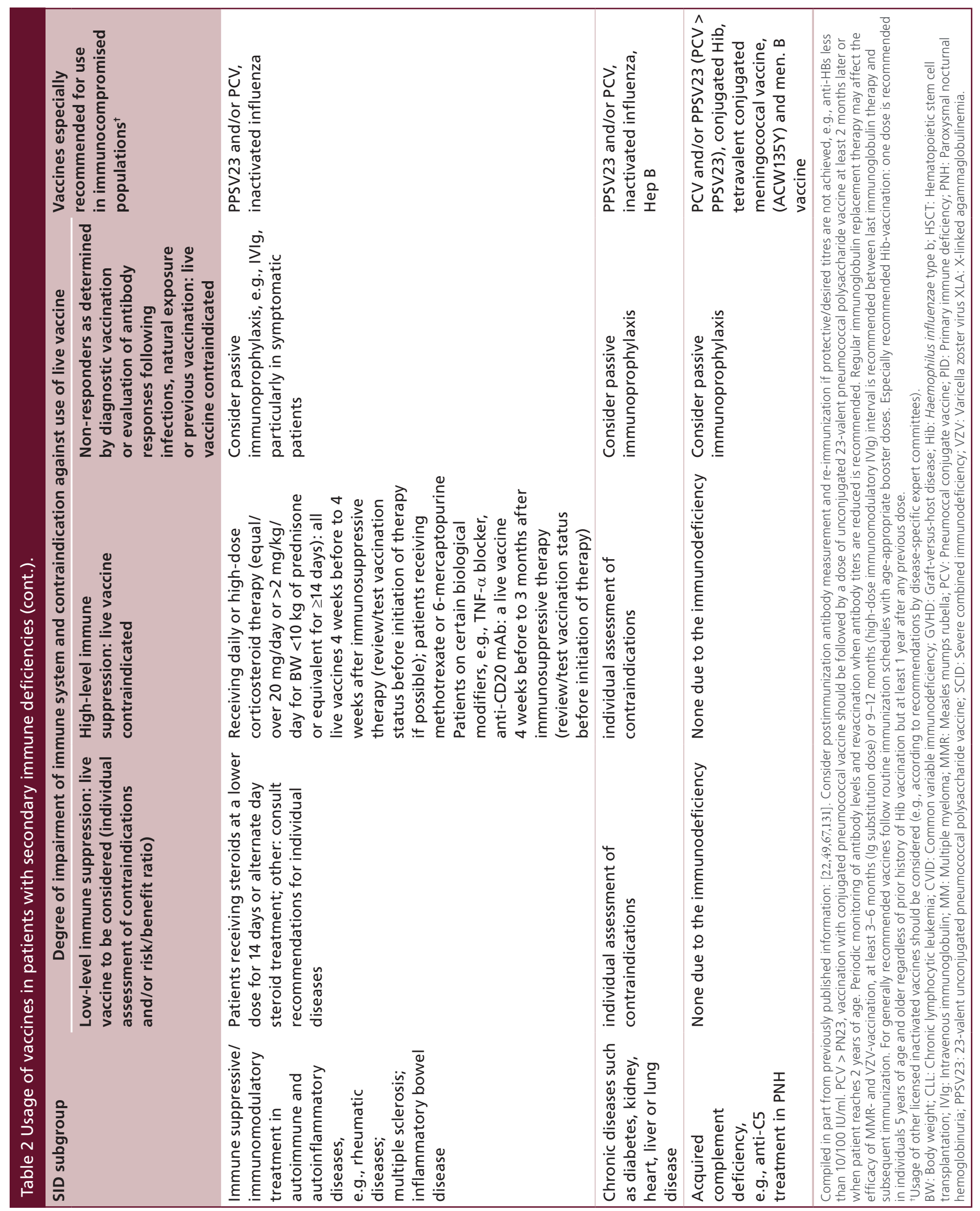




\section{HIV infection}

Patients infected with HIV might be severely immunesuppressed or they might be on antiviral treatment and have minimal impairment of the immune response. Based on risk benefit assessment by expert groups, different recommendations are given for patients with $\leq 200 \mathrm{CD} 4 \mathrm{~T}$ cells/ $\mu \mathrm{l}$ and for patients $>200 \mathrm{CD} 4 \mathrm{~T}$ cells/ $\mu \mathrm{l}$ (200-500 and above) (Table 2). For patients with $\mathrm{CD} 4 \mathrm{~T}$ cells $\leq 200$ cells $/ \mu \mathrm{l}$ all live vaccines are contraindicated. In low-level immunocompromised patients the benefits of vaccination with certain live vaccines far outweighs the possible risk. The recommendations are based on extensive studies in the HIV-infected population and have been applied in other SID entities, even though the underlying mechanisms responsible for the immune deficiency are inherently different. It is currently recommended that HIV patients should be especially vaccinated against influenza, pneumococcal infection, Hib and hepatitis B (Hep B), as well as meningococcal disease $[14,15,89]$. Immunization of HIV-positive individuals against hepatitis A ( $\mathrm{Hep} \mathrm{A})$ is especially recommended if chronic hepatitis $\mathrm{B}$ or $\mathrm{C}$ is present, in injection drug users or men having sex with men, as well as in HIV-positive international travelers or hemophiliacs. VZV and MMR vaccination should be considered for patients, in particular children, with HIV infection who have more than $200 \mathrm{CD} 4$ cells/ $\mu \mathrm{l}$ (adults) or more than $15 \%$ of CD 4 as percent of lymphocytes (children below the age of 6 years), as the disease might be more severe in the immune-compromised.

There is ongoing discussion and controversy on the risk/benefit assessment of varicella vaccination in pediatric HIV as in other pediatric populations with SID, especially with respect to childhood acute lymphoblastic leukemia (ALL) [90]. In these patients, varicella vaccine should only be administered as a single vaccine, and not in combination with MMR [22,91,92]. Herpes zoster might cause a devastating disease in patients with SID. Zoster vaccine is recommended for patients over 60 years of age, 4 weeks or more before the start of highly immune-suppressive treatment. Patients who are immunocompromised because of transplant medication or HIV have a higher burden of human papilloma virus (HPV)-associated disease and cancer. Even though HPV antibody titers were lower in the immunocompromised following vaccination, immunization is still recommended [11].

\section{Malignant hematologic disorders \& malignant solid tumors}

Similar rules as in HIV have been established based on risk/benefit assessment relying on the epidemiology of infectious diseases in lymphoreticular malignancies such as children with leukemia, patients with lym- phoma, patients with multiple myeloma (MM) and patients with other, different forms of cancer [93,94]. In patients with cancer impairment of immunity may be part of the disease, as is the case in hematological malignancies such as multiple myeloma, chronic lymphocytic leukemia (CLL) and lymphoma, or the consequence of immune suppression due to chemotherapy [90]. Inactivated vaccines against influenza, $\mathrm{Hib}$ and pneumococcal infection are especially recommended in cancer patients (Table 2). In cancer patients in general it is important to start immunization at the earliest possible time point, however without interfering with the schedule of immune-suppressive treatment. If vaccination is started before immunosuppression it likely has to be repeated 4-6 months after intensive chemotherapy. If it is not possible to start before, it should be applied after chemotherapy (see timing) and the application of higher vaccine doses has been attempted in individual diseases (IDSA recommendations) $[22,95,96]$.

\section{HSCT \& solid organ transplantation}

Special recommendations cover vaccination with respect to types of inactivated vaccines indicated (Table 2), as well as timing and dosing in patients with HSCT and in patients with solid organ transplants. HSCT transplantation recommendations cover vaccination of the donor as well as of household contacts. The donor is vaccinated with the aim of inducing a strong immune response, vaccination with the recommended vaccines should be started at the earliest time point after presentation [97].

\section{Immunosuppressive \& immunomodulatory treatment in autoimmune \& autoinflammatory disease}

Patients with different autoimmune diseases who require immunosuppressive treatment differ greatly in immune competence and the degree of susceptibility to infection, and this is taken into consideration in the recommendations by expert committees for individual diseases [98]. Immune-suppressive treatment may be followed by high- and/or low-level impairment of immune function (Table 2), depending on the time and the extent of therapy, the drugs used and/ or whether biologicals are applied [80]. Special recommendations for vaccination in patients under immunesuppressive treatment are given by several national and international health agencies and professional groups (Table 2). Patients with rheumatic diseases are often treated with long-term, high-dosed corticosteroids, high-grade immune-suppressive drugs and/or biologicals (Rituximab) and biological immune modifiers, for example, TNF- $\alpha$ antagonists and disease-specific recommendations have to be adhered to $[72,79,82,99,100-102]$. 
Special vaccine recommendations are also defined in patients treated with other biological immunomodulatory drugs, for example, paroxysmal nocturnal hemoglobinuria $(\mathrm{PNH})$ patients treated with anti-C5 monoclonal antibody (Table 2).

\section{Chronic diseases (diabetes \&/or kidney, liver,} lung, heart disease)

Diabetes, especially in the elderly, may be complicated by chronic kidney disease, heart disease, liver disease and lung disease, putting those patients at even higher risk for infections $[16,103]$.

Patients with chronic kidney, lung, heart and/or liver disease may be immunocompromised and show increased susceptibility to infection [104-106]. These reports confirm the increased susceptibility to infection and recommend vaccination (Table 2). Patients with chronic organ failure, who may have to be treated by organ transplantation, should, if possible, be vaccinated before organ transplantation [105].

\section{Individual vaccines especially important in immunocompromised populations}

Vaccinations are recommended with priority against diseases for which evidence exists that they contribute to increased morbidity and mortality in immunocompromised populations [16,94]. Vaccination with PCV and PPSV as well as yearly vaccination with inactivated influenza vaccine is strongly recommended for all immunocompromised patients (Table 2). Live influenza vaccine should not be used in SID. Further special recommendations include Hib- and meningococcal vaccine, as well as hepatitis $B$ vaccine $[22,67,86]$. Recommendations take into consideration risk/benefit and benefit/cost evaluation. Numerous small studies have addressed these questions and demonstrate small risk of these vaccinations versus high risk of the respective infections $[76,77,79,81,82]$. Advisory authorities state that large population studies are scarce in the immunocompromised groups, but based on the evidence available $[67,107,108]$ vaccination with the above mentioned vaccines (inactivated influenza, pneumococcal vaccine, Hib vaccine, meningococcal vaccine and $\mathrm{Hep} \mathrm{B)}$ is strongly recommended (Table 2). Recommendations are updated yearly as new studies become available. Although it is known that adaptive immune responses, for example, antibody production is often impaired in immunocompromised patients [109] the effectiveness in terms of protection has been shown [107].

\section{Influenza vaccines}

Special importance has been paid to immunization of different SID populations against seasonal (and pandemic) influenza and against pneumococcal infections as these diseases are a special threat in the immune compromised population. Indication, dosage and timelines are updated continuously as population-based results become available. Inactivated influenza vaccine can be safely administered to all immunocompromised patients of 6 months of age or older receiving immunosuppressive treatment, oncology patients receiving chemotherapy, immunosuppressed transplant patients or patients infected with HIV [64,100,110-112]. The vaccine is also safe and vaccination response is usually good in patients with chronic systemic inflammatory diseases [113]. Antibody response is often poor in patients receiving intensive cancer chemotherapy, in patients receiving infliximab or rituximab and in transplant recipients while receiving intensive immune suppression [82]. A study of antibody-deficient patients on (intravenous immunoglobulin) IVIg treatment shows good safety but poor immunogenicity [70]. Influenza infection in solid organ transplant recipients is often associated with significant morbidity, and CDC recommendations led to an increase in the percentage of patients receiving annual inactivated influenza vaccine [16]. A recent meta-analysis showed that in 209 eligible studies, a median of 60 immunocompromised patients per study received active influenza vaccination (interquartile range [IQR] 36 to 110), in other words, a total of 12,540 patients (median) were examined [64]. Fiftyeight studies were in patients with HIV-infection, 56 studies in cancer patients, 52 studies included transplant recipients, 34 studies dealt with patients suffering from autoimmune diseases requiring immunosuppressive therapy. Only few studies assessed influenza vaccination in patients with other immunocompromising conditions, for example, PID or respiratory diseases receiving immunosuppressive therapy. Meta-analyses showed a significant effect of preventing influenza-like illness (odds ratio [OR]: 0.23 ; 95\% CI: 0.16-0.34; p $=0.001)$ and laboratory confirmed influenza infection (OR: 0.15 ; 95\% CI: $0.03-0.63$; $\mathrm{p}=0.01$ ) through vaccinating immunocompromised patients as compared with placebo or unvaccinated controls [64]. In addition, no difference in the odds of influenza-like illness was found between vaccinated immunocompromised populations and immunocompetent controls. Also in this meta-analysis indication for a suboptimal vaccineinduced immune response could be found, as the pooled odds of seroconversion were lower in vaccinated patients compared with immunocompetent controls for seasonal influenza $\mathrm{A}(\mathrm{H} 1 \mathrm{~N} 1), \mathrm{A}(\mathrm{H} 3 \mathrm{~N} 2)$ and $\mathrm{B}$. A similar trend was identified for seroprotection, in other words, evaluating individuals with a postvaccination antibody level above a certain cut-off level considered to confer $50 \%$ protection. No consistent evidence of safety concerns regarding influenza vaccination in 
immunocompromised populations was identified in this large meta-analysis.

\section{Pneumococcal vaccines}

A recent CDC recommendation states that both PCV and PPSV23 should be administered routinely to all adults 65 years of age and older [30,114]. Vaccination against pneumococcal disease is safe and strongly recommended also in immunocompromised patients. Pneumococcal disease is an important cause for morbidity and mortality in immune compromised populations, as the antibody response to pneumococcal polysaccharide antigens, as shown by testing vaccination responses, is suboptimal [115]. A large controlled randomized study demonstrated the efficacy of vaccination with the nine-valent pneumoccal conjugate vaccine (PCV7) in children with and without HIV infection. The prospective study took place from March 1998 to October 2000 and included 39,836 children, of which 19,922 were randomly chosen to receive the nine-valent conjugate vaccine and 19,914 received placebo. Follow-up continued until mid November 2001. The efficacy of the vaccine for the predefined primary endpoint of invasive pneumococcal disease was $85 \%$ in children of the same age group without HIV infection, while for HIV-infected children the efficacy against vaccine serotypes was $65 \%$ [57]. First episodes of invasive pneumonia by antibiotic resistant pneumococcal strains (penicillin and trimethoprim-sulfamethoxazole) were significantly reduced in all children by vaccination, and in HIV positive children as well, while stratification into smaller/different groups did not show significant differences in efficacy [116]. The CDC recommends PCV vaccination followed by PPSV23 vaccination in children (aged 6-18 years) immunocompromised due to congenital or acquired immunodeficiency, human immunodeficiency virus infection, chronic renal failure, nephrotic syndrome, leukemia, lymphoma, Hodgkin disease or other hematological malignancy, generalized malignancy, iatrogenic immunosuppression, solid organ transplant, anatomic or functional asplenia (including sickle cell disease), cochlear implant or cerebrospinal fluid (CSF) leak [108]. In addition, PCV vaccination followed by PPSV23 vaccination is also recommended in immunocompromised adults such as persons with functional or anatomic asplenia, sickle cell disease/other hemaglobinopathy, congenital or acquired asplenia, congenital or acquired immunodeficiency, human immunodeficiency virus infection, chronic renal failure, nephrotic syndrome, leukemia, lymphoma, Hodgkin disease, generalized malignancy, iatrogenic immunosuppression, solid organ transplant or multiple myeloma [117].
In addition to PCV, the application of PPSV-23 has been generally recommended and emphasized for the following populations and can be seen in the following recommendations: children 6-18 years [108], HIV-infected persons [76], HIV-infected children [81] and HIV-infected adults [118]. Important for pediatricians is the recommendation that children with SID above 2 years of age should receive PCV, followed by PPSV23 (at least 2 months later). This includes children with the following clinical conditions: chronic heart disease, chronic lung disease including asthma if treated with high dose of corticosteroids, diabetes, cerebral spinal fluid leaks, cochlar implants, children with functional asplenia and in general, in children on immune-suppressive treatment (Table 2).

\section{Hib vaccine}

In 2014 recommendations for Hib vaccination were updated. The vaccine is recommended for patients with increased risk who have not been vaccinated against Hib-infection before [55]. More recent evidence has led to recommend Hib vaccine also to the susceptible adult immunocompromised patients [119,120]. Individuals with certain immunocompromising conditions (PID and SID) are considered at an increased risk for Hib. Adults who have received a successful HSCT should receive three doses of Hib 6-12 months after the transplant, vaccination is also recommended in functional and/or anatomic asplenia, HIV infection, antibody deficiency syndromes, early complement component deficiencies, patients on chemotherapy or radiation therapy for malignant neoplasms.

\section{Meningococcal vaccines}

For immunization against meningococcal disease vaccines containing polysaccharides derived from four meningococcal strains (ACWY) conjugated to a carrier are licensed and available. In addition to binding titers (e.g., antibody levels as assessed by ELISA) several studies assessed bactericidal titers in vaccines. Complement-dependent bactericidal activity can be reliably assessed by using human or baby rabbit serum as a complement source. In patients who develop meningococcal disease, bactericidal antibodies were often absent in pre-infection serum samples [45,121].

ACIP recommends vaccination against meningococcal infection for all children aged $>6$ weeks (bivalent $\mathrm{MCV}$ and $H$. influenzae type b conjugate vaccine HibMenCY), $\geq 2$ months (quadrivalent MCV conjugated to the diphtheria toxin mutant CRM197 MenACWYCRM) or $\geq 9$ months (quadrivalent MCV conjugated to diphtheria toxoid MenACWY-D), depending on the vaccine used. Detailed age-specific recommendations are given. Vaccination with a tetravalent 
meningococcal vaccine is especially recommended for microbiologists who are routinely exposed to meningitis-causing bacteria, and persons who travel to countries where meningococcal disease is hyperendemic, as well as for immunocompromised populations, for example, persons with primary complement component deficiencies (C3, C5-9, Properdin, Factor D), patients with an acquired complement deficiency such as $\mathrm{PNH}$ patients treated with anti-C5 $\mathrm{mAb}$, patients who have anatomic or functional asplenia (including patients after splenectomy) and persons at risk during a community outbreak attributable to a vaccine serogroup, $[14,15,89,121,122]$. Several small studies in patients with SID in different disease entities are in favor of vaccination in the populations studied. $[9,54,121]$.

\section{Hepatitis B vaccination}

The risk for hepatitis B virus (HBV)-infection in diabetic adult patients aged 23-59 years of age was 2.1-times higher compared with healthy individuals but this is supposedly under estimated, with the gray zone being ten-times higher. Both the incidence and severity of acute hepatitis $B$ in patients with diabetes is increased. Questions about time and dose of vaccination also include the possibility of a shortened duration of the response. Revaccination with 1-3 additional doses of Hep $\mathrm{B}$ vaccine is safe and increases protection [77]. The cost-effectiveness has also been documented $[6,86,99,106,122-126]$. In addition, hepatitis B vaccination is recommended in populations immunocompromised due to HIV infection, end-stage renal disease including patients receiving hemodialysis, chronic liver disease. Adult patients receiving hemodialysis or with other immunocompromising conditions should be vaccinated with a double vaccine dose $(40 \mu \mathrm{g} / \mathrm{ml})$ of recombinant hepatitis B surface antigen $[15,89]$.

\section{Vaccination of household members \& healthcare personnel}

To protect patients who cannot be vaccinated and/or who cannot respond to vaccination against vaccinepreventable diseases (the most vulnerable PID and SID patients), household members of PID and SID patients should be vaccinated and should be well-informed about the risk for the patient by viral/bacterial shedding in the course of infection/vaccination of close contacts $[16,26,49]$. These individuals are advised to be vaccinated with recommended killed and certain, but not all, live vaccines. There is no special contraindication against vaccination with MMR in these household members. Special recommendations are applied, however, for live viral vaccinations, which are followed by viral shedding, for example, rotavirus vaccination and live influenza virus vaccination [127,128]. This also applies to yellow fever vaccines and live/attenuated bacterial vaccines, mainly used for travelers. Vaccination with all recommended inactivated vaccines is strongly recommended especially against vaccine-preventable diseases playing an important role in morbidity and mortality of the immunocompromised [75]. According to CDC guidelines, household members should receive inactivated influenza vaccine, MMR vaccine and varicella vaccine. They should not be administered oral polio vaccine. Paralytic polio is known to occur in immune-deficient contacts of persons vaccinated with oral polio vaccine [75]. Both primary care providers and specialists caring for immunocompromised patients are responsible for vaccination of their patients, as well as for advising for vaccination of their household members $[22,67,124]$. Recent studies demonstrate that the rate of life-saving vaccination in the immunocompromised mainly relies on advice and incentive of primary care physicians and specialists involved in the patients' care and follow-up [129]. Similar to household members, healthcare workers caring for and following patients with PID and/or SID are advised to receive all live and killed vaccines according to the recommendations of immunization for the adult population, especially against infectious diseases which constitute a higher risk in the PID/SID population [22,67,126].

\section{Timing of application of live \& killed vaccines}

In immunodeficient/immunosuppressed populations the timing of vaccination is of special importance [22]. The main objective is to cause no harm. To achieve this goal in patients who will be immune suppressed during the course of their therapies, vaccination should be started, if possible, as soon as the patient presents for medical care to increase the time between vaccination and maximal immune suppression. As a most conservative recommendation [67], 4 months before initiation of maximum immune suppression are considered as safe for the application of live vaccines. In these conditions, nonsimultaneous administration of different vaccines has been recommended for MMR and varicella vaccine (VAR) in SID instead of MMRVAR [130]. However, depending on the clinical entity, safety margins might be different and may be shortened even to 4 weeks before immune suppression. This explains certain discrepancies between recommendations of different health authorities - for example, Canadian versus ACIP [67]. Vaccination may have to be repeated 6 weeks or more after chemotherapy [67,93].

In the case of attenuated live viral vaccines, multiplication of the constituents is essential for immunization. Antibodies in the host inhibit viral multiplication 
in a dose-dependent manner, and interfere with vaccination $[28,29]$. If these vaccines are applied in patients with minor or light immunodeficiency with very low serum antibody levels (below protective levels), but not with antibody failure, control of positive response after vaccination involves antibody determination. Patients with different forms of predominantly antibody deficiency might have very low antibody titer, for example, antibodies against measles, and whether they do or do not respond after measles vaccination cannot be predicted, so titers will have to be checked after vaccination.

Low dose RHOGAM (anti-D immunoglobulin) does not interfere with post partum rubella vaccination. In patients on immune globulin treatment, the time difference required between the last immunoglobulin application and live vaccination is dose-dependent and given on the package insert of the respective immunoglobulin products $[28,29,131]$.

Killed vaccines have been evaluated and are considered to be safe and protective in the immunocompromised population, even though the immune response is lower in height and breadth as compared with the immune response of the healthy population [78,111]. Theoretically it means antibody titer and polyclonality with respect to immunological phenotype - regarding treatment decisions it means that the patient is able to respond to some, but not to all antigens. Timing, dosing and spacing of these vaccines is important to maximize efficacy. $[6,118,132]$. The administration of killed vaccines should be started as soon as possible before immune-suppressive treatment. If this is not possible, it should be preferentially given after severe immunosuppression. This applies to cancer, chemotherapy, as well as solid organ transplantation and HSCT [110].

It is well-known from numerous studies that response to vaccination in the PID, SID and IRA patient populations is significantly lower in quantity and quality as compared with the general population $[104,109,120,133-135]$. For this reason, repeating vaccinations and increasing the dose-defining optimal intervals have been analyzed in numerous studies and based on the results of these studies, optimal criteria for timing and dosing have been included in the recommendations for individual vaccines. Determination of serum antibody titers is optional to assess booster requirement $[6,100,118,136,137]$.

Recent and ongoing studies address the question of optimal dosing for the population with impairment of immune function. The question whether the increase of the antigen dose in certain vaccines could improve the response has been asked. Another possibility is to administer instead of one two or more doses of vaccine at monthly or bimonthly intervals [77].

\section{Future persepctive}

PIDs are hetergeneous genetic disorders classified by single gene mutations causing impairment of a defined pathway in innate and/or adaptive immunity. The degree of immune impairment has been studied in great detail in the different groups of PID patients: severe combined T- and B-cell immunodeficiency, combined immunodeficiency and the spectrum of patients with predominantly antibody deficiency syndromes ranging from complete antibody failure to less severe antibody deficiency such as selective antibody deficiency. There are more vaccination studies in the different patient populations with SID than with PID, and further studies would be important. Comprehensive recommendation for vaccination of PID patients has been put forward by the ASIP with the aim to prevent severe forms of vaccine-preventable diseases. In these recommendations indications and contraindications for live and killed vaccines, as established in larger studies of SID populations, have been applied. OPV and BCG are contraindicated in all immunocompromised patients. Live vaccines are contraindicated in severe T-cell and severe B-cell immune deficiencies and are differentially applied in low-level immune impairment. Evaluation of the risk/benefit ratio is based both on the character of the immunodeficiency and the immunological phenotype of the patient.

Larger studies have been performed in children and adults with HIV in different parts of the world. Thorough analysis of these studies led to recommendations for the application of live vaccines in patients with different stages of HIV disease as characterized by their numbers of $\mathrm{CD}^{+} \mathrm{T}$ cells. Killed vaccines are recommended in these patient populations and have been shown to be protective, even though the immune response is below the response of the healthy population. In addition to HIV infection, secondary immunodeficencies develop in the course of a great variety of different disease entitites. Because of the vast heterogeneity of diseases, vaccination studies are numerous, but limited in the number of patients included in each study. Diagnostic/therapeutic studies have been performed in cancer patients including hematological malignancies and solid organ tumors, in different stages of cancer. In these patients SIDs arise as a consequence of disease or chemotherapy. Recommendations of vaccination for recipients, donors and household members of HSCT patients are updated yearly. In patients with chronic heart, lung, liver and kidney disease and patients with solid organ transplants, individual studies and studies applying meta-analysis have clearly indicated the effectivity of vaccination in reducing morbidity and hospitalization, and even mortality. Patients with different forms of autoimmune disease 


\section{Background}

- Prevention of infectious diseases and its complications by available vaccines is among the most effective and most important healthcare measures in the general population and in patients with primary immune deficiency (PID), secondary immune deficiency (SID) and immune-regulatory abnormalities (IRA) as well.

- Numerous small and medium-sized vaccination studies in SID patients with different diseases proved reduction of severe infectious episodes, and even mortality, hospitalization, intensive care treatment and treatment costs.

- Guidelines recommend vaccination as part of medical care; the primary physician and specialist directing patient care are responsible for vaccination.

\section{Definition \& diagnosis of PID}

- Patients with PID usually present with increased susceptibility to infection, but first manifestations may also include autoimmune and systemic inflammatory disease.

- Primary immunodeficiencies are caused by more than 200 known single-gene mutations that may affect the number and the function of immune cells.

- PID diagnosis requires thorough and detailed evaluation of T cell, B cell and innate immunity.

- Predominantly antibody deficiencies represent at least $50 \%$ of all clinically symptomatic PID patients.

- Diagnostic vaccination with inactivated vaccines is safe and important, also for treatment decisions. Assessment of the antibody response after vaccination in immunocompromised patients is easy, robust and gives a clear basis for high- and low-grade immune impairment and immune failure.

Vaccination in PID

- All killed vaccines are safe and are strongly recommended for PID patients. Immunization should follow the same rules as used in the general population.

- Vaccination with live vaccines, for example, rotavirus, MMR, VAR, live influenza, oral polio vaccine is principally contraindicated in patients with severe impairment of immunological function. This is not the case in populations with no or minimal impairment of adaptive immunity.

\section{Definition \& diagnosis of SID}

- Secondary immunodeficiencies develop in the course of different diseases and in consequence of immune suppressive and/or immune modulatory treatment.

- SID patients are a heterogeneous population with HIV-infection, hematological malignancies, malignant solid tumors, HSCT recipients, solid organ transplants, immune-suppressive/immune modulatory treatment in autoimmune and systemic inflammatory diseases such as rheumatic disease, multiple sclerosis, inflammatory bowe disease, chronic diseases such as diabetes, kidney, heart, liver, lung disease and acquired complement deficiency

- Vaccine-preventable infectious diseases lead to increased morbidity and mortality in these patient populations.

- The impairment in immune defense may be at various levels (B cell, T cell innate immunity), and involve multiple mechanisms simultaneously.

- Assessment of the impairment - high-level, low-level, antibody failure - is important for treatment decisions.

Vaccination in SID \& special vaccines indicated

- Vaccination against diseases contributing to morbidity and mortality - PCV and PPSV23 and yearly inactivated influenza - are recommended with priority.

- Other specially recommended vaccines include Hib, Men-ACWY quadrivalent conjugated meningococcal vaccines and Hep B.

- Live vaccines are contraindicated in all SID patients with high-level immune suppression. For patients with low-level immune impairment critical evaluation of the risk-benefit ratio of individual live vaccines by an experienced clinical immunologist is necessary.

Vaccination of household members \& healthcare personnel

- Vaccination of household members will help to protect the most vulnerable SID patients with antibody failure, and individuals who are too young or too ill to respond, and others who cannot be vaccinated.

Timing of application of killed vaccines

- Vaccination in the immunocompromised should be performed as early as possible, if feasible, at presentation.

- Reports indicate that SID patients may require a higher dose and/or more frequent immunizations.

Conclusion \& future perspective

- PID, SID and IRA patient populations are highly undervaccinated.

- Vaccination in PID patients may improve quality of life and prognosis and could facilitate early diagnosis and treatment decisions.

- In SID patients better vaccination coverage could reduce infectious complications, and thus be life saving.

- Evaluation and monitoring of the immune response in these patient populations would define and differentiate high level versus low level and transient short-term versus permanent immune impairment. This could improve treatment decisions, reduce complications of disease, hospitalization and costs. 
differ greatly with respect to disease characteristics and treatment options. Patients with diabetes often have chronic heart or kidney disease aggravating the level of immune impairment, leading to organ failure. Rheumatic patients are often treated with high-dose corticosteroids, cytostatic drugs and/or biologicals causing severe immune suppression. Several vaccination studies have been performed in all of these disease groups. In several of the studies, however, the degree of immune suppression has not been fully taken into consideration and the results are thus inconclusive.

New studies based on the level of immune suppression in single disease entities may provide more homogeneous results. Studies in HIV-infected defined the level of immune suppression based on CD4 counts; along these lines estimation of immune impairment in the immunologic laboratory could define high and low levels of immune suppression in other forms of SID as well, for example, in cancer patients. Semiquantative assessment of antibody production, for example, by comparison of antibody levels pre and post vaccination with inactivated protein and polysaccharide vaccines could differentiate between high-level and low-level immune suppression and immune failure. Even though diagnostic vaccination with killed vaccines has generally been recommended, it has mainly been restricted to booster immunization with a pneumococcal polysaccharide vaccine. Further studies will be needed to support decisions on treatment indications for vaccination, passive

\section{References}

1 Chapel HM, Christie JM, Peach V, Chapman RW. Five-year follow-up of patients with primary antibody deficiencies following an outbreak of acute hepatitis C. Clin. Immunol. 99(3), 320-324 (2001).

2 Kunisaki KM, Janoff EN. Influenza in immunosuppressed populations: a review of infection frequency, morbidity, mortality, and vaccine responses. Lancet Infect. Dis. 9(8), 493-504 (2009).

3 Zbinden D, Manuel O. Influenza vaccination in immunocompromised patients: efficacy and safety. Immunotherapy 6(2), 131-139 (2014).

4 Vandecasteele SJ, Ombelet S, Blumental S, Peetermans WE. The ABC of pneumococcal infections and vaccination in patients with chronic kidney disease. Clin. Kidney J. 8(3), 318-324 (2015).

5 Tomblyn M, Chiller T, Einsele H et al. Guidelines for preventing infectious complications among hematopoietic cell transplantation recipients: a global perspective. Biol. Blood Marrow Transplant. 15(10), 1143-1238 (2009).

6 Launay O, van d V, Rosenberg AR et al. Safety and immunogenicity of 4 intramuscular double doses and 4 intradermal low doses vs standard hepatitis $B$ vaccine regimen in adults with HIV-1: a randomized controlled trial. JAMA 305(14), 1432-1440 (2011). immunoprophylaxis by immunoglobulin replacement and temporary addition of antibiotics, antifungal and antiviral medication. The avenue of studying stratified groups of SID patients with different underlying diseases, but with comparable immune impairment could possibly open new ways to clinical studies enabling assessment of vaccination efficacy in larger populations.

\section{Acknowledgements}

The authors thank N Stich for fruitful discussion and help with literature search, and C Blank for help in preparing the manuscript.

\section{Financial \& competing interests disclosure}

The authors have no relevant affiliations or financial involvement with any organization or entity with a financial interest in or financial conflict with the subject matter or materials discussed in the manuscript. This includes employment, consultancies, honoraria, stock ownership or options, expert testimony, grants or patents received or pending, or royalties.

No writing assistance was utilized in the production of this manuscript.

\section{Open access}

This article is distributed under the terms of the Creative Commons Attribution License 4.0 which permits any use, distribution, and reproduction in any medium, provided the original author(s) and the source are credited. To view a copy of the license, visit http://creativecommons.org/licenses/by/4.0/

$7 \quad$ Knipe DM, Whelan SP. Rethinking the response to emerging microbes: vaccines and therapeutics in the ebola era - a conference at Harvard Medical School. J. Virol. 89(15), 7446-7448 (2015).

8 Mina MJ, Metcalf CJ, de Swart RL, Osterhaus AD, Grenfell BT. Vaccines. Long-term measles-induced immunomodulation increases overall childhood infectious disease mortality. Science 348(6235), 694-699 (2015).

9 Infant meningococcal vaccination: advisory Committee on Immunization Practices (ACIP) recommendations and rationale. MMWR Morb. Mortal. Wkly Rep. 62(3), 52-54 (2013).

10 Grohskopf LA, Olsen SJ, Sokolow LZ et al. Prevention and control of seasonal influenza with vaccines: recommendations of the Advisory Committee on Immunization Practices (ACIP) - United States, 2014-2015 influenza season. MMWR Morb. Mortal. Wkly Rep. 63(32), 691-697 (2014).

11 Markowitz LE, Dunne EF, Saraiya M et al. Human papillomavirus vaccination: recommendations of the Advisory Committee on Immunization Practices (ACIP). MMWR Recomm. Rep. 63(RR-05), 1-30 (2014).

12 Bridges CB, Coyne-Beasley T. Advisory Committee on Immunization Practices recommended immunization schedule for adults aged 19 years or older - United States, 2014. MMWR Morb. Mortal. Wkly Rep. 63(5), 110-112 (2014). 
13 Grohskopf LA, Shay DK, Shimabukuro TT et al. Prevention and control of seasonal influenza with vaccines. Recommendations of the Advisory Committee on Immunization Practices - United States, 2013-2014. MMWR Recomm. Rep. 62(RR-07), 1-43 (2013).

14 Strikas RA. Advisory committee on immunization practices recommended immunization schedules for persons aged 0 through 18 years - United States, 2015. MMWR Morb. Mortal. Wkly Rep. 64(4), 93-94 (2015).

15 Kim DK, Bridges CB, Harriman KH. Advisory committee on immunization practices recommended immunization schedule for adults aged 19 years or older United States, 2015. MMWR Morb. Mortal. Wkly Rep. 64(4), 91-92 (2015).

16 Chon WJ, Kadambi PV, Harland RC et al. Changing attitudes toward influenza vaccination in U.S. Kidney transplant programs over the past decade. Clin. J. Am. Soc. Nephrol. 5(9), 1637-1641 (2010).

17 Morrill HJ, Caffrey AR, Noh E, LaPlante KL. Epidemiology of pneumococcal disease in a national cohort of older adults. Infect. Dis. Ther. 3(1), 19-33 (2014).

18 Vinograd I, Baslo R, Eliakim-Raz $\mathrm{N}$ et al. Factors associated with influenza vaccination among adult cancer patients: a case-control study. Clin. Microbiol. Infect. 20(9), 899-905 (2014).

19 Cesaro S, Giacchino M, Fioredda F et al. Guidelines on vaccinations in paediatric haematology and oncology patients. Biomed. Res. Int. 2014, 707691 (2014).

20 Multiple Sclerosis Council. Clinical Practice Guidelines. Immunizations and Multiple Sclerosis: Evidence-Based Management Strategies for Immunizations in Multiple Sclerosis. (2001)

21 Principi N, Esposito S. Vaccine use in primary immunodeficiency disorders. Vaccine 32(30), 3725-3731 (2014).

22 Rubin LG, Levin MJ, Ljungman P et al. 2013 IDSA clinical practice guideline for vaccination of the immunocompromised host. Clin. Infect. Dis. 58(3), 309-318 (2014).

23 Bernstein HH, Starke JR. Policy statement recommendation for mandatory influenza immunization of all health care personnel. Pediatrics 126(4), 809-815 (2010).

24 Babcock HM, Gemeinhart N, Jones M, Dunagan WC, Woeltje KF. Mandatory influenza vaccination of health care workers: translating policy to practice. Clin. Infect. Dis. 50(4), 459-464 (2010).

25 Crawford NW, Heath JA, Ashley D, Downie P, Buttery JP. Survivors of childhood cancer: an Australian audit of vaccination status after treatment. Pediatr. Blood Cancer 54(1), 128-133 (2010).

26 Urun Y, Akbulut H, Demirkazik A et al. Perception about influenza and pneumococcal vaccines and vaccination coverage among patients with malignancies and their family members. J. BUON 18(2), 511-515 (2013).

27 KDIGO clinical practice guideline for the care of kidney transplant recipients. Am. J. Transplant. 9(Suppl. 3), S1-S155 (2009).
28 Centers for Disease Control and Prevention. General recommendations on immunization. In: Epidemiology and Prevention of Vaccine-Preventable Diseases

(12th Edition). Hamborsky J, Kroger A, Wolfe S (Eds). Public Health Foundation, Washington DC (2012).

29 Centers for Disease Control and Prevention. In: Epidemiology and Prevention of Vaccine-Preventable Diseases (13th Edition).Hamborsky J, Kroger A, Wolfe S (Eds). Public Health Foundation, Washington DC (2015).

30 American Diabetes Association. Standards of medical care in diabetes - 2014. Diabetes Care 37(Suppl. 1), S14-S80 (2014).

31 Al-Herz W, Bousfiha A, Casanova JL et al. Primary immunodeficiency diseases: an update on the classification from the international union of immunological societies expert committee for primary immunodeficiency. Front. Immunol. 5, 162 (2014).

32 Chapel H, Prevot J, Gaspar HB et al. Primary immune deficiencies - principles of care. Front. Immunol. 5, 627 (2014).

33 Azar AE, Ballas ZK. Evaluation of the adult with suspected immunodeficiency. Am. J. Med. 120(9), 764-768 (2007).

34 Carneiro-Sampaio M, Coutinho A. Early-onset autoimmune disease as a manifestation of primary immunodeficiency. Front. Immunol. 6, 185 (2015).

35 Pessach IM, Notarangelo LD. X-linked primary immunodeficiencies as a bridge to better understanding X-chromosome related autoimmunity. J. Autoimmun. 33(1), 17-24 (2009).

36 Cavaliere FM, Milito C, Martini $\mathrm{H}$ et al. Quantification of $\operatorname{IgM}$ and IgA anti-pneumococcal capsular polysaccharides by a new ELISA assay: a valuable diagnostic and prognostic tool for common variable immunodeficiency. J. Clin. Immunol. 33(4), 838-846 (2013).

37 Wolf HM, Thon V, Litzman J, Eibl MM. Detection of impaired IgG antibody formation facilitates the decision on early immunoglobulin replacement in hypogammaglobulinemic patients. Front. Immunol. 6, 32 (2015).

38 Borrow R, Balmer P, Miller E. Meningococcal surrogates of protection - serum bactericidal antibody activity. Vaccine 23(17-18), 2222-2227 (2005).

39 Martinez LJ, Lin L, Blaylock JM, Lyons AG, Bauer KM, De La BR et al. Safety and immunogenicity of a dengue virus serotype-1 purified-inactivated vaccine: results of a phase 1 clinical trial. Am. J. Trop. Med. Hyg. Pii:14-0819 (2015) (Epub ahead of print).

40 Pedersen GK, Hoschler K, Oie Solbak SM et al. Serum IgG titres, but not avidity, correlates with neutralizing antibody response after H5N1 vaccination. Vaccine 32 (35), 4550-4557 (2014).

41 van d V, Geisberger A, Dvorak T et al. Safety and immunogenicity of a vero cell culture-derived wholevirus $\mathrm{H} 5 \mathrm{~N} 1$ influenza vaccine in chronically ill and immunocompromised patients. Clin. Vaccine Immunol. 21(6), 867-876 (2014).

42 Rabenau HF, Marianov B, Wicker S, Allwinn R. Comparison of the neutralizing and ELISA antibody titres 
to measles virus in human sera and in gamma globulin preparations. Med. Microbiol. Immunol. 196(3), 151-155 (2007).

Banaszkiewicz A, Radzikowski A. Efficacy, effectiveness, immunogenicity - are not the same in vaccinology. World J. Gastroenterol. 19(41), 7217-7218 (2013).

arrera E, Manzano R, Garrido E. Efficacy of the vaccination in inflammatory bowel disease. World J. Gastroenterol. 19(9), 1349-1353 (2013).

Andrews N, Borrow R, Miller E. Validation of serological correlate of protection for meningococcal $\mathrm{C}$ conjugate vaccine by using efficacy estimates from postlicensure surveillance in England. Clin. Diagn. Lab. Immunol. 10(5), 780-786 (2003).

Hangartner L, Zinkernagel RM, Hengartner H. Antiviral antibody responses: the two extremes of a wide spectrum. Nat. Rev. Immunol. 6(3), 231-243 (2006).

47 Prelog M. Vaccination in Patients with Rheumatoid Arthritis Receiving Immunotherapies. J. Clin. Cell Immunol. S6-007 (2013).

48 Lobermann M, Borso D, Hilgendorf I, Fritzsche C, Zettl UK, Reisinger EC. Immunization in the adult immunocompromised host. Autoimmun. Rev. 11(3), 212-218 (2012).

49 Shearer WT, Fleisher TA, Buckley RH et al. Recommendations for live viral and bacterial vaccines in immunodeficient patients and their close contacts. J. Allergy Clin. Immunol. 133(4), 961-966 (2014).

50 Sewell WA, Kerr J, Behr-Gross ME, Peter HH. European consensus proposal for immunoglobulin therapies. Eur. J. Immunol. 44(8), 2207-2214 (2014).

51 Yong PL, Boyle J, Ballow M et al. Use of intravenous immunoglobulin and adjunctive therapies in the treatment of primary immunodeficiencies: a working group report of and study by the Primary Immunodeficiency Committee of the American Academy of Allergy Asthma and Immunology. Clin. Immunol. 135(2), 255-263 (2010).

52 Jolles S, Orange JS, Gardulf A et al. Current treatment options with immunoglobulin $\mathrm{G}$ for the individualization of care in patients with primary immunodeficiency disease. Clin. Exp. Immunol. 179(2), 146-160 (2015).

53 Orange JS, Ballow M, Stiehm ER et al. Use and interpretation of diagnostic vaccination in primary immunodeficiency: a working group report of the Basic and Clinical Immunology Interest Section of the American Academy of Allergy, Asthma \& Immunology. J. Allergy Clin. Immunol. 130(3 Suppl.), S1-S24 (2012).

54 MacNeil JR, Rubin L, McNamara L, Briere EC, Clark TA, Cohn AC. Use of MenACWY-CRM vaccine in children aged 2 through 23 months at increased risk for meningococcal disease: recommendations of the Advisory Committee on Immunization Practices, 2013. MMWR Morb. Mortal. Wkly Rep. 63(24), 527-530 (2014).

55 Briere EC, Rubin L, Moro PL, Cohn A, Clark T, Messonnier N. Prevention and control of Haemophilus influenzae type $\mathrm{b}$ disease: recommendations of the advisory committee on immunization practices (ACIP). MMWR Recomm. Rep. 63(RR-01), 1-14 (2014).
56 Committee to Review Adverse Effects of Vaccines, Institute of Medicine, Stratton K, Ford A, Rusch E, Clayton EW. Adverse Effects of Vaccines: Evidence and Causality. National Academies Press (2011).

57 Klugman KP, Madhi SA, Huebner RE, Kohberger R, Mbelle $\mathrm{N}$, Pierce N. A trial of a 9-valent pneumococcal conjugate vaccine in children with and those without HIV infection. N. Engl. J. Med. 349 (14), 1341-1348 (2003).

58 Plebani A, Fischer MB, Meini A, Duse M, Thon V, Eibl MM. T cell activity and cytokine production in X-linked agammaglobulinemia: implications for vaccination strategies. Int. Arch. Allergy Immunol. 114(1), 90-93 (1997).

59 Carsetti R, Rosado MM, Donnanno $S$ et al. The loss of IgM memory B cells correlates with clinical disease in common variable immunodeficiency. J. Allergy Clin. Immunol. 115(2), 412-417 (2005).

60 Paroli M, Accapezzato D, Francavilla V et al. Long-lasting memory-resting and memoryeffector $\mathrm{CD}^{+}{ }^{+} \mathrm{T}$ cells in human X-linked agammaglobulinemia. Blood 99(6), 2131-2137 (2002).

61 Morales-Aza B, Glennie SJ, Garcez TP et al. Impaired maintenance of naturally acquired T-cell memory to the meningococcus in patients with B-cell immunodeficiency. Blood 113(18), 4206-4212 (2009).

62 Amedei A, Romagnani C, Benagiano M et al. Preferential Th1 profile of T helper cell responses in X-linked (Bruton's) agammaglobulinemia. Eur. J. Immunol. 31(6), 1927-1934 (2001).

63 Pedersen G, Halstensen A, Sjursen H, Naess A, Kristoffersen EK, Cox RJ. Pandemic influenza vaccination elicits influenza-specific $\mathrm{CD} 4^{+} \mathrm{Th} 1$-cell responses in hypogammaglobulinaemic patients: four case reports. Scand. J. Immunol. 74(2), 210-218 (2011).

64 Beck CR, McKenzie BC, Hashim AB et al. Influenza vaccination for immunocompromised patients: systematic review and meta-ana-lysis from a public health policy perspective. PLoS ONE 6(12), e29249 (2011).

65 DeVries AS, Harper J, Murray A et al. Vaccine-derived poliomyelitis 12 years after infection in Minnesota. N. Engl. J. Med. $364(24)$, 2316-2323 (2011).

66 Eliakim-Raz N, Vinograd I, Zalmanovici TA, Leibovici $\mathrm{L}$, Paul M. Influenza vaccines in immunosuppressed adults with cancer. Cochrane Database Syst. Rev. 10, CD008983 (2013).

67 Tamblyn SE. Canadian Immunization Guide (4th Edition). Can. J. Infect. Dis. 5(3), 105-106 (1994).

68 Hofstetter AM, Jakob K, Klein NP et al. Live vaccine use and safety in DiGeorge syndrome. Pediatrics 133(4), e946-e954 (2014).

69 Pedersen G, Halstensen A, Sjursen H, Naess A, Kristoffersen EK, Cox RJ. Pandemic influenza vaccination elicits influenza-specific $\mathrm{CD} 4^{+}$Th1-cell responses in hypogammaglobulinaemic patients: four case reports. Scand. J. Immunol. 74(2), 210-218 (2011).

70 van AS, Holvast A, Telgt DS et al. Patients with humoral primary immunodeficiency do not develop protective anti- 
influenza antibody titers after vaccination with trivalent subunit influenza vaccine. Clin. Immunol. 136(2), 228-235 (2010).

71 Duraisingham SS, Buckland MS, Grigoriadou S, Longhurst HJ. Secondary antibody deficiency. Expert Rev. Clin. Immunol. 10(5), 583-591 (2014).

72 Strangfeld A, Listing J, Herzer P et al. Risk of herpes zoster in patients with rheumatoid arthritis treated with anti-TNFalpha agents. JAMA 301(7), 737-744 (2009).

73 Tai LH, Zhang J, Scott KJ et al. Perioperative influenza vaccination reduces postoperative metastatic disease by reversing surgery-induced dysfunction in natural killer cells. Clin. Cancer Res. 19(18), 5104-5115 (2013).

74 Wyplosz B, Lafarge M, Escaut L, Stern JB. Fatal measles pneumonitis during Hodgkin's lymphoma. BMJ Case Rep.2013, doi:10.1136/bcr-2013-200252 (2013).

75 Chemaly RF, Vigil KJ, Saad M et al. A multicenter study of pandemic influenza A (H1N1) infection in patients with solid tumors in 3 countries: early therapy improves outcomes. Cancer 118(18), 4627-4633 (2012).

76 Dworkin MS, Ward JW, Hanson DL, Jones JL, Kaplan JE. Pneumococcal disease among human immunodeficiency virus-infected persons: incidence, risk factors, and impact of vaccination. Clin. Infect. Dis. 32(5), 794-800 (2001).

77 Fonseca MO, Pang LW, de Paula CN, Barone AA, Heloisa LM. Randomized trial of recombinant hepatitis $B$ vaccine in HIV-infected adult patients comparing a standard dose to a double dose. Vaccine 23(22), 2902-2908 (2005).

78 Eckerle I, Rosenberger KD, Zwahlen M, Junghanss T. Serologic vaccination response after solid organ transplantation: a systematic review. PLoS ONE 8(2), e56974 (2013).

79 Askling HH, Rombo L, van VR et al. Hepatitis A vaccine for immunosuppressed patients with rheumatoid arthritis: a prospective, open-label, multi-centre study. Travel. Med. Infect. Dis. 12(2), 134-142 (2014).

80 Bar-Or A, Freedman MS, Kremenchutzky M et al. Teriflunomide effect on immune response to influenza vaccine in patients with multiple sclerosis. Neurology 81(6), 552-558 (2013).

81 Abzug MJ, Pelton SI, Song LY et al. Immunogenicity, safety, and predictors of response after a pneumococcal conjugate and pneumococcal polysaccharide vaccine series in human immunodeficiency virus-infected children receiving highly active antiretroviral therapy. Pediatr. Infect. Dis. J. 25(10), 920-929 (2006)

82 Del PF, Lagana B, Biselli R et al. Influenza vaccine administration in patients with systemic lupus erythematosus and rheumatoid arthritis. Safety and immunogenicity. Vaccine 24(16), 3217-3223 (2006).

83 Centers for Disease Control and Prevention. Updated recommendations for use of tetanus toxoid, reduced diphtheria toxoid and acellular pertussis vaccine (Tdap) in pregnant women and persons who have or anticipate having close contact with an infant aged $<12$ months - Advisory Committee on Immunization Practices (ACIP), 2011. MMWR Morb. Mortal. Wkly Rep. 60(41), 1424-1426 (2011).
84 Musher DM. Pneumococcal vaccination in adults (2015). www.uptodate.com

85 Mouthon L, Fermand JP, Gottenberg JE. Management of secondary immune deficiencies: what is the role of immunoglobulins?. Curr. Opin. Allergy Clin. Immunol. 13 (Suppl. 2), S56-S67 (2013).

86 Use of hepatitis B vaccination for adults with diabetes mellitus: recommendations of the Advisory Committee on Immunization Practices (ACIP). MMWR Morb. Mortal. Wkly Rep. 60(50), 1709-1711 (2011).

87 van AS, Agmon-Levin N, Elkayam O et al. EULAR recommendations for vaccination in adult patients with autoimmune inflammatory rheumatic diseases. Ann. Rheum. Dis. 70 (3), 414-422 (2011).

88 Chapel HM, Lee M. The use of intravenous immune globulin in multiple myeloma. Clin. Exp. Immunol. 97(Suppl. 1), 21-24 (1994).

89 General recommendations on immunization recommendations of the Advisory Committee on Immunization Practices (ACIP). MMWR Recomm. Rep. 60(2), 1-64 (2011).

90 Caniza MA, Hunger SP, Schrauder A, Valsecchi MG, Pui $\mathrm{CH}$, Masera $\mathrm{G}$. The controversy of varicella vaccination in children with acute lymphoblastic leukemia. Pediatr. Blood Cancer 58(1), 12-16 (2012).

91 Naidus E, Damon L, Schwartz BS, Breed C, Liu C. Experience with use of $\operatorname{Zostavax}((\mathrm{R}))$ in patients with hematologic malignancy and hematopoietic cell transplant recipients. Am. J. Hematol. 87(1), 123-125 (2012).

92 Updated recommendations for use of VariZIG-United States, 2013. MMWR Morb. Mortal. Wkly Rep. 62(28), 574-576 (2013).

93 Bochennek K, Allwinn R, Langer R et al. Differential loss of humoral immunity against measles, mumps, rubella and varicella-zoster virus in children treated for cancer. Vaccine 32(27), 3357-3361 (2014).

94 Robin C, Beckerich F, Cordonnier C. Immunization in cancer patients: where we stand. Pharmacol. Res. 92, 23-30 (2015).

95 Hicks LK, Woods A, Buckstein R et al. Rituximab purging and maintenance combined with autoSCT: long-term molecular remissions and prolonged hypogammaglobulinemia in relapsed follicular lymphoma. Bone Marrow Transplant. 43(9), 701-708 (2009).

96 Raanani P, Gafter-Gvili A, Paul M, Ben-Bassat I, Leibovici L, Shpilberg O. Immunoglobulin prophylaxis in hematological malignancies and hematopoietic stem cell transplantation. Cochrane Database Syst. Rev. 4, CD006501 (2008).

97 Blombery P, Prince HM, Worth LJ et al. Prophylactic intravenous immunoglobulin during autologous haemopoietic stem cell transplantation for multiple myeloma is not associated with reduced infectious complications. Ann. Hematol. 90 (10), 1167-1172 (2011).

98 Pedrazzoli P, Baldanti F, Donatelli I et al. Vaccination for seasonal influenza in patients with cancer: recommendations of the Italian Society of Medical Oncology (AIOM). Ann. Oncol. 25(6), 1243-1247 (2014). 
99 Gisbert JP, Villagrasa JR, Rodriguez-Nogueiras A, Chaparro $M$. Efficacy of hepatitis B vaccination and revaccination and factors impacting on response in patients with inflammatory bowel disease. Am. J. Gastroenterol. 107(10), 1460-1466 (2012).

100 Aikawa NE, Trudes G, Campos LM et al. Immunogenicity and safety of two doses of a non-adjuvanted influenza $\mathrm{A}$ H1N1/2009 vaccine in young autoimmune rheumatic diseases patients. Lupus 22(13), 1394-1398 (2013).

101 Kogure T, Harada N, Tatsumi T, Fujinaga H. Investigation of clinical characteristics as predictive factors for the humoral immune response to the influenza vaccine in patients with rheumatoid arthritis. Clin. Rheumatol. 33(3), 323-328 (2014).

102 Saad CG, Borba EF, Aikawa NE et al. Immunogenicity and safety of the 2009 non-adjuvanted influenza A/H1N1 vaccine in a large cohort of autoimmune rheumatic diseases. Ann. Rheum. Dis. 70(6), 1068-1073 (2011).

103 Soni R, Horowitz B, Unruh M. Immunization in end-stage renal disease: opportunity to improve outcomes. Semin. Dial. 26(4), 416-426 (2013).

104 Watcharananan SP, Thakkinstian A, Srichunrasmee C, Chuntratita W, Sumethkul V. Comparison of the immunogenicity of a monovalent influenza A/H1N1 2009 vaccine between healthy individuals, patients with chronic renal failure, and immunocompromised populations. Transplant. Proc. 46(2), 328-331 (2014).

105 Martins WA, Ribeiro MD, Oliveira LB et al. Influenza and pneumococcal vaccination in heart failure: a little applied recommendation. Arq. Bras. Cardiol. 96(3), 240-245 (2011).

106 Qu C, Chen T, Fan C et al. Efficacy of neonatal HBV vaccination on liver cancer and other liver diseases over 30 year follow-up of the Qidong hepatitis B intervention study: a cluster randomized controlled trial. PLoS Med. 11(12), e1001774 (2014)

107 Pollyea DA, Brown JM, Horning SJ. Utility of influenza vaccination for oncology patients. J. Clin. Oncol. 28(14), 2481-2490 (2010).

108 Centers for Disease Control and Prevention. Use of 13-valent pneumococcal conjugate vaccine and 23 -valent pneumococcal polysaccharide vaccine among children aged 6-18 years with immunocompromising conditions: recommendations of the Advisory Committee on Immunization Practices (ACIP). MMWR Morb. Mortal. Wkly Rep. 62(25), 521-524 (2013).

109 Rosen HR, Stierer M, Wolf HM, Eibl MM. Impaired primary antibody responses after vaccination against hepatitis B in patients with breast cancer. Breast Cancer Res. Treat. 23(3), 233-240 (1992).

110 Wumkes ML, van d, V Los M et al. Serum antibody response to influenza virus vaccination during chemotherapy treatment in adult patients with solid tumours. Vaccine 31(52), 6177-6184 (2013).

111 Kim DH, Lee YY, Shin US, Moon SM. Immunogenicity of influenza vaccine in colorectal cancer patients. Cancer Res. Treat. 45(4), 303-312 (2013).

112 Shehata MA, Karim NA. Influenza vaccination in cancer patients undergoing systemic therapy. Clin. Med. Insights Oncol. 8, 57-64 (2014).
113 Romio S, Weibel D, Dieleman JP et al. Guillain-Barre syndrome and adjuvanted pandemic influenza A (H1N1) 2009 vaccines: a multinational self-controlled case series in Europe. PLoS ONE 9(1), e82222 (2014).

114 Tomczyk S, Bennett NM, Stoecker C et al. Use of 13 -valent pneumococcal conjugate vaccine and 23 -valent pneumococcal polysaccharide vaccine among adults aged $>$ / $=65$ years: recommendations of the Advisory Committee on Immunization Practices (ACIP). MMWR Morb. Mortal. Wkly Rep. 63(37), 822-825 (2014).

115 Madhi SA, Klugman KP, Kuwanda L, Cutland C, Kayhty $\mathrm{H}$, Adrian P. Quantitative and qualitative anamnestic immune responses to pneumococcal conjugate vaccine in HIV-infected and HIV-uninfected children 5 years after vaccination. J. Infect. Dis. 199(8), 1168-1176 (2009).

116 French N, Gordon SB, Mwalukomo T et al. A trial of a 7-valent pneumococcal conjugate vaccine in HIV-infected adults. N. Engl. J. Med. 362(9), 812-822 (2010).

117 Centers for Disease Control and Prevention. Use of 13 -valent pneumococcal conjugate vaccine and 23 -valent pneumococcal polysaccharide vaccine for adults with immunocompromising conditions: recommendations of the Advisory Committee on Immunization Practices (ACIP). MMWR Morb. Mortal. Wkly Rep. 61(40), 816-819 (2012).

118 Lesprit P, Pedrono G, Molina JM et al. Immunological efficacy of a prime-boost pneumococcal vaccination in HIVinfected adults. AIDS 21(18), 2425-2434 (2007).

119 Madhi SA, Kuwanda L, Saarinen L et al. Immunogenicity and effectiveness of Haemophilus influenzae type b conjugate vaccine in HIV infected and uninfected African children. Vaccine 23(48-49), 5517-5525 (2005).

120 Nix EB, Hawdon N, Gravelle S et al. Risk of invasive Haemophilus influenzae type $\mathrm{b}$ (Hib) disease in adults with secondary immunodeficiency in the post-Hib vaccine era. Clin. Vaccine Immunol. 19(5), 766-771 (2012).

121 Cohn AC, MacNeil JR, Clark TA et al. Prevention and control of meningococcal disease: recommendations of the Advisory Committee on Immunization Practices (ACIP). MMWR Recomm. Rep. 62(RR-2), 1-28 (2013).

122 Kuehn BM. Immunization recommendations expanded for hepatitis B, HPV, pertussis vaccines. JAMA 307(13), 1353-1354 (2012).

123 Grzegorzewska AE, Pajzderski D, Sowinska A, Mostowska A, Jagodzinski PP. IL4R and IL13 polymorphic variants and development of antibodies to surface antigen of hepatitis $B$ virus in hemodialysis patients in response to $\mathrm{HBV}$ vaccination or infection. Vaccine 31(14), 1766-1770 (2013).

124 Schillie S, Murphy TV, Sawyer M et al. CDC guidance for evaluating health-care personnel for hepatitis $\mathrm{B}$ virus protection and for administering postexposure management. MMWR Recomm. Rep. 62(RR-10), 1-19 (2013).

125 Holmberg SD, Suryaprasad A, Ward JW. Updated CDC recommendations for the management of hepatitis $\mathrm{B}$ virus-infected health-care providers and students. $M M W R$ Recomm. Rep. 61(RR-3), 1-12 (2012).

126 Shefer A, Atkinson W, Friedman C et al. Immunization of health-care personnel: recommendations of the Advisory 
Committee on Immunization Practices (ACIP). MMWR Recomm. Rep. 60(RR-7), 1-45 (2011).

127 Payne DC, Edwards KM, Bowen MD et al. Sibling transmission of vaccine-derived rotavirus (RotaTeq) associated with rotavirus gastroenteritis. Pediatrics 125(2), e438-e441 (2010).

128 Rivera L, Pena LM, Stainier I et al. Horizontal transmission of a human rotavirus vaccine strain - a randomized, placebocontrolled study in twins. Vaccine 29(51), 9508-9513 (2011).

129 Poeppl W, Lagler H, Raderer $\mathrm{M}$ et al. Influenza vaccination perception and coverage among patients with malignant disease. Vaccine 33(14), 1682-1687 (2015).

130 Klein NP, Fireman B, Yih WK et al. Measles-mumpsrubella-varicella combination vaccine and the risk of febrile seizures. Pediatrics 126(1), e1-e8 (2010).

131 Centers for Disease Control and Prevention. Recommendations of the Advisory Committee on Immunization Practices (ACIP), use of vaccines and immune globulins for persons with altered immunocompetence. MMWR Recomm. Rep. 42(RR-4), 1-18 (1993).

132 Ek T, Josefson M, Abrahamsson J. Multivariate analysis of the relation between immune dysfunction and treatment intensity in children with acute lymphoblastic leukemia. Pediatr. Blood Cancer 56(7), 1078-1087 (2011).
133 Olberg HK, Cox RJ, Nostbakken JK, Aarseth JH, Vedeler $\mathrm{CA}$, Myhr KM. Immunotherapies influence the influenza vaccination response in multiple sclerosis patients: an explorative study. Mult. Scler. 20 (8), 1074-1080 (2014).

134 McCarthy CL, Tuohy O, Compston DA, Kumararatne DS, Coles AJ, Jones JL. Immune competence after alemtuzumab treatment of multiple sclerosis. Neurology 81(10), 872-876 (2013)

135 Pasiarski M, Rolinski J, Grywalska E et al. Antibody and plasmablast response to 13 -valent pneumococcal conjugate vaccine in chronic lymphocytic leukemia patients preliminary report. PLoS ONE 9(12), el14966 (2014).

136 McManus M, Frangoul H, McCullers JA, Wang L, O'Shea A, Halasa N. Safety of high dose trivalent inactivated influenza vaccine in pediatric patients with acute lymphoblastic leukemia. Pediatr. Blood Cancer 61(5), 815-820 (2014).

137 McMahan ZH, Bingham CO III. Effects of biological and non-biological immunomodulatory therapies on the immunogenicity of vaccines in patients with rheumatic diseases. Arthritis Res. Ther. 16(6), 506 (2014).

138 Mitteilung der Ständigen Impfkommission (STIKO) am Rober Koch Institut: Hinweise zu Impfungen für Patienten mit Immundefizienz. Robert Koch Institut (Ed.). Epidem. Bull. 39, 353-364 (2005). 